\title{
MANILKARA ADANS. (SAPOTACEAE) OCORRENTE NA REGIÃO SEMIÁRIDA DO NORDESTE BRASILEIRO
}

\author{
$\underline{\text { Ana Flavia Trabuco Duarte }}{ }^{1}$; Claudia Elena Carneiro ${ }^{2}$ \\ 1. Bolsista PIBIC/CNPq, Graduanda em Ciências Biológicas, Universidade Estadual de Feira de Santana, e- \\ mail: flavia.trabuco@hotmail.com \\ 2. Orientador, Departamento de Ciências Biológicas, Universidade Estadual de Feira de Santana, e-mail: \\ cecarneiro@gmail.com
}

PALAVRAS-CHAVE: Morfologia; taxonomia; florística.

\section{INTRODUÇÃO}

De acordo com as análises filogenéticas do Grupo Filogenético de Angiospermas (APG IV 2016), Sapotaceae está no clado Asterídea, dentro da ordem Ericales, apresentando uma maior similaridade filogenética com Ebenaceae e Pentaphylacaceae. A família compreende 58 gêneros com aproximadamente 1.250 espécies predominantemente pantropical, com alta diversidade em regiões tropicais e subtropicais da América do Sul e Ásia, encontradas especialmente em florestas úmidas (Swenson \& Anderberg 2005), sendo facilmente reconhecida pela combinação do látex, com o arranjo e venação das folhas (Gentry 1993). Sapotaceae ocupa lugar de destaque na flora brasileira, com 202 espécies distribuídas em 12 gêneros, sendo que 101 espécies são endêmicas do país (Carneiro et al. 2015). Manilkara Adans. é considerado o quarto maior gênero de Sapotaceae, com 78 espécies pantropicais, sendo 30 nas Américas Central e do Sul, 35 na África e 13 no Sudeste da Ásia (Armstrong et al. 2010). No Neotrópico, ocorre na costa litorânea e na região amazônica do Brasil, além do Paraguai, Uruguai e Chile, sendo caracterizado pelo cálice em duas séries, presença de estaminódios e a forma do hilo (Pennington 1990). Segundo Andrade (1957), no Brasil o gênero apresenta maior representatividade em áreas de Restinga e Mata Atlântica. Almeida Jr. (2010) realizou estudos que esclareceram a distribuição geográfica do gênero e o estado de conservação das espécies para o Nordeste do Brasil, registrando 12 espécies que se diferenciam, principalmente, pela quantidade de flores, tamanho de pecíolo e pedicelo, filotaxia, variação da folha e do indumento. No Brasil, 16 espécies foram registradas, destas, 11 ocorrem em Mata Atlântica, e 8 na Amazônia (Flora do Brasil 2020). No Nordeste do Brasil, o gênero está distribuído ao longo do litoral da Floresta Atlântica (stricto sensu) e na Caatinga (Farias et al. 2004). Atualmente, o Nordeste é a região brasileira com maior número de espécies do gênero, com 13 espécies registradas (Flora do Brasil 2020). O nordeste do Brasil tem uma área de aproximadamente 1.542.248 $\mathrm{km}^{2}$ (IBGE 1998), o bioma do semiárido ocupa cerca de $750.000 \mathrm{~km} 2$ deste território (Ab'Saber 1984). O semiárido ocupa 10\% do território brasileiro e abriga uma população de cerca de 21 milhões de pessoas o que corresponde a $11 \%$ da população brasileira, e vem se tornado cada dia mais urbano (Ab’Saber 2003), e com isso, sua riqueza natural vem sofrendo com os fenômenos de antropização. O que demonstra uma importância em estudar as espécies que ocorrem nesta região, afim de avaliar o seu potencial de distribuição e status de conservação.

\section{METODOLOGIA}


Foi realizado um levantamento bibliográfico sobre as espécies do gênero Manilkara Adans. que ocorrem no semiárido nordestino, através de estudos taxonômicos, envolvendo livros, teses, monografias e floras, e informações contidas em exsicatas que estão depositadas em herbários através de consultas físicas e virtuais. As exsicatas foram analisadas através de visita física ao HUEFS, e consulta virtual ás obras príncipes para uma melhor identificação, as análises dos caracteres morfológicos foram realizadas de maneira usual em estudos taxonômicos, através da análise de exsicatas e com auxilio de bibliografias específicas, buscando dados que são diagnósticos paras as espécies.

\section{RESULTADOS E/OU DISCUSSÃO}

O gênero Manilkara Adans. está representado no semiárido nordestino por dez espécies, as quais foram devidamente identificadas utilizando bibliografias específicas. $\mathrm{O}$ resultado deste estudo morfológico e taxonômico é apresentado a seguir.

Manilkara Adans.

Árvore ou arbusto, látex branco abundante em toda a planta. Estípulas ausentes ou presentes. Folha simples, alterna, folhas dispostas no ápice dos ramos cilíndricos, elípticas a oblanceoladas, tricomas ferrugíneos a amarelados podem estar presentes em face abaxial, venação broquidódroma. Flores solitárias ou em fascículos axilares, pequenas, não vistosas, diclamídeas, monoicas, 6 sépalas agrupadas em duas séries de 3 , pétalas divididas em três segmentos, estaminódio petalóide, ovário súpero, glabro ou tomentoso. Fruto baga, semente elipsoide, comprimida lateralmente.

O gênero encontra-se dentro da subtribo Manilkarinae, de acordo com a classificação de Pennington (1990). Armstrong (2010) sugeriu o monofiletismo do clado, suportado por análises de parcimônia e Bayesianas. Manilkarinae tem sido distinguida das outras subtribos da família Sapotaceae pelos seguintes caracteres: presença de cálice em duas séries, com cada uma composta por três sépalas, uma corola com seis pétalas, cada pétala muitas vezes dividida em três segmentos, o segmento médio ereto e oposto ao estame, distinto dos segmentos laterais, estaminódios variando na forma e alternando com estames, fruto indeiscente, cicatriz da semente geralmente alongada, base-ventral (Pennington 1991).

As espécies são pantropicais, com ca. 30 espécies nas Américas, ca. 20 na África e Madagascar e ca. 15 na Ásia e na região do Pacífico (Pennington, 1991). No Brasil há 16 espécies, com ocorrência em florestas ombrófilas e restingas ao longo da costa (Almeida, 2010).

De acordo com esse estudo, foi possível elaborar uma chave de identificação para as espécies analisadas.

Chave de identificação para as espécies de Manilkara ocorrentes na região semiárida nordestina

1 Flores solitárias.

2 Pecíolo medindo 1,6-2,3 cm de comprimento; folhas com ápice arredondado e base obtusa 1. Manilkara dardanoi 2' Pecíolo medindo 3,2-3,7 cm de comprimento; folhas com ápice emarginado e base estreita cuneiforme 5. Manilkara maxima

1' Flores em fascículos.

3 Ovário cônico, face abaxial da folha com tomento amarronzado ao longo da nervura central 10. Manilkara zapota 3' Ovário ovóide, face abaxial da folha tomentosa ou folha glabra em ambas as faces. 
4 Pecíolo com 0,5-0,7 cm de comprimento; folha glabra em ambas as faces

9. Manilkara triflora

4' Pecíolo com mais de $0,7 \mathrm{~cm}$ de comprimento; folha tomentosa a glabra na face abaxial.

5 Folha com ápice emarginado e base obtusa, tomentosa na face abaxial 6. Manilkara multifida

5' Folha com ápice arredondado a obtuso e base variável, glabra a ligeiramente tomentosa na face abaxial.

6 Folhas estreitamente cuneiformes, com ápice obtuso e base cuneiforme

6' Folhas elípticas a oblanceoladas, com base aguda a obtusa.

4. Manilkara longifolia

7 Pedicelo com 2,0-2,2 cm de comprimento; ovário tomentoso

7. Manilkara rufula

7' Pedicelo menor que 2,2 cm de comprimento; ovário glabro.

8 Folhas oblanceoladas a elípticas com base estreitamente aguda, nervura central não canaliculada; pecíolo com até $1,4 \mathrm{~cm}$ de comprimento 8. Manilkara salzmannii

8' Folhas elípticas a oblanceoladas com base obtusa a aguda, nervura central canaliculada; pecíolo maior que $1,4 \mathrm{~cm}$ de comprimento.

9 Estípulas presentes e reduzidas; folhas com ápice obtuso; segmento mediano da corola levemente naviculado; cicatriz do pecíolo elíptica

3. Manilkara elata

9' Estípulas ausentes; folhas com ápice arredondado; segmento mediano da corola estreitamente naviculado; cicatriz do pecíolo arredondada

2. Manilkara decrescens

\section{CONSIDERAÇÕES FINAIS}

A partir do presente estudo de caracteres morfológicos e dos registros de distribuição e status de conservação para as espécies de Manilkara do semiárido foi possível, estabelecer regiões para conservação e preservação de espécies que já se encontram na lista de espécies ameaçada, além da elaboração de uma chave de identificação para as espécies estudadas, que destaca as características diagnosticas de cada espécie do gênero.

\section{REFERÊNCIAS}

Ab’Saber, N.A. 1984. O domínio morfoclimático semiárido das caatingas brasileiras. Instituto de Geografia / USP. São Paulo, Brasil.

Ab’Saber, N.A. 2003. Os domínios de natureza no Brasil: potencialidades paisagísticas. São Paulo: Ateliê Editorial. São Paulo, Brasil.

Almeida Jr., E. B. Morfoanatomia Foliar de Manilkara Adans. (Sapotaceae) do Nordeste Brasileiro. 2010. Universidade Federal Rural de Pernambuco.158p.(46-118).

APG IV, The Angiosperm Phylogeny Group.2016. An update of the Angiosperm Phylogeny Group classification for the orders and families of flowering plants: APG IV. 
Armstrong, K. 2010. Systematics and biogeography of the pantropical genus Manilkara Adans. (Sapotaceae)., Royal Botanic Garden and University of Edinburgh, Edinburgh, 244p. Botanical Journal of the Linnean Society 181: 1-20.

Carneiro, C.E.; Alves-Araujo, A.; Almeida Jr., E.B.; Terra-Araujo, M.H.2016. Sapotaceae in Lista de Espécies da Flora do Brasil. Jardim Botânico do Rio de Janeiro. http://reflora.jbrj.gov.br/jabot/floradobrasil/FB217 (09/07/2017).

Flora do Brasil 2020 em construção. Jardim Botânico do Rio de Janeiro. Disponível em: < http://floradobrasil.jbrj.gov.br/ >. Acesso em: 05 Jul. 2017.

Gentry, A.H. 1993. A field guide to the families and genera of woody plants of northeast South America. Washington, D.C.: Conservation International,1993.

IBGE- Instituto Brasileiro de Geografia e Estatísticas. 1988. Anuário Estatístico do Brasil. Rio de Janeiro, Brasil.

Pennington, T.D. 1990. Sapotaceae. In Flora Neotropica, The New York Botanical Garden, v.52.

Swenson, U.; Anderberg, A.A. 2005. Phylogeny, character evolution, and classification of Sapotaceae (Ericales). Cladistics 21: 101-130. 